\title{
PRESENTACIÓN GRÁFICA, DESPLAZAMIENTO Y APROBACIÓN DE LA NATURALEZA EN LAS EXPEDICIONES BOTÁNICAS DEL SIGLO XVIII
}

\section{Mauricio Nieto}

\section{RESUMEN}

En este trabajo me propongo ilustrar el papel central que juegan las representaciones visuales en la exploración botánica. Me baso para ello en documentos (gráficos y escritos) tanto de la escuela de pintura de José Celestino Mutis en Santa Fe de Bogotá, los cuales nos informan sobre el entrenamiento de artistas y ei proceso de elaboración de láminas, al igual que en los diarios de Ruiz y Pavón durante la publicación de la Flora Peruviana. Se destaca la función activa del artista en el proceso de clasificación (fabricación) de nuevas especies.

\section{SUMMARY}

My purpose, on this work, is to illustrate the central role that plays the visual representations on the botanical exploration. I used documents (graphics and written) from the school of painting of José Celestino Mutis in Santa Fe de Bogotá, that informs 


\title{
MAURICIO NIETO
}

\begin{abstract}
us about artists' training and the process of elaboration of sheets; the same as in the newspapers of Ruiz and Pavón during the publication of the Flora Peruviana. The artist's in the process of classification (construction) of new species active function stands out.
\end{abstract}

En repetidas ocasiones se ha señalado cómo los viajes de exploración constituyeron un foco de interés intelectual, político y comercial de los distintos imperios europeos del siglo XVIII ${ }^{1}$. La historia natural del período ilustrado, veremos más adelante, constituyó una forma de apropiación y jugó un papel central en las políticas imperiales europeas.

Los viajeros naturalistas retornaron al Viejo Mundo con numerosas colecciones de objetos naturales, plantas y animales vivos o disecados, muestras minerales, semillas, y detallados informes escritos o visuales. Pero sobre todo, y en particular los exploradores españoles, se vieron embarcados en la producción de extensas y elaboradas colecciones de ilustraciones botánicas, que con sus correspondientes descripciones linneanas, serían publicadas en España. Las láminas y sus descripciones constituirían el material de lujosas y costosas publicaciones, una muestra tangible de los logros de las expediciones y un símbolo de poder y soberanía del estado español. Ciertamente, todos los grandes soberanos, desde los Medici hasta los Habsburgo y Borbones, recopilaron colecciones iconográficas de objetos naturales procedentes de sus colonias u otras tierras lejanas.

Hasta hace poco, los historiadores y sociólogos de la ciencia habían subestimado la función de las formas visuales de comunicación en la práctica científica. Sin embargo, recientes publicaciones en la materia, como por ejemplo, la recopilación de ensayos Representation in scientific practice, editada por Michael Lynch y Steve Woolgar, ofrece nuevas herramientas para una mejor apreciación del lenguaje visual en la historia de la ciencia ${ }^{2}$. Algunos investigadores se han ocupado de las ilustraciones

\footnotetext{
1 Ver por ejemplo Brockway, L. H. (1979); McClelan, J. E. III (1992); Mackay, D. (1985) o las distintas contribuciones al volumen Visions of Empire (en imprenta).

2 LyNCH, M. y WoOlgar, S. (eds.) (1990), Representation in scientific practice, Cambridge, Mass: The MITT Press. Ver artículo de Latour, B., «Drawing things together", pp. 19-68. Por el mismo autor, "Visualization and cognition: thinking with
} 
botánicas del siglo XVIII, pero sus análisis se han concentrado en aspectos de carácter estético relacionados con la historia del arte. ${ }^{3}$ Sin desconocer la importancia de dichos trabajos y sus valiosas contribuciones, la presente investigación tiene otros intereses. En lo que sigue, me propongo explorar la participación activa del ilustrador de plantas en la clasificación y apropiación de objetos naturales.

Como punto de partida, debemos tener en mente que para los naturalistas linneanos del siglo XVIII, las láminas que veremos más adelante, representan especies vegetales. Es decir, objetos naturales y reales, las unidades inmutables de la obra del Creador. Por otra parte, las plantas del Nuevo Mundo se presentaron en Europa como descubrimientos. Y como veremos adquirieron el carácter de posesiones, convirtiéndose, muchas veces, en artículos de enorme valor comercial.

Nuestro propósito será entonces exponer los procesos y negociaciones que hicieron posible promulgar dichos «descubrimientos», como también hacer explícita la relación entre los conceptos de descubrimiento científico y apropiación.

Veamos entonces a los naturalistas en acción y examinemos sus técnicas y habilidades.

En oposición a las obras de arte, imaginarias y fantasiosas, las ilustraciones botánicas presuponían un fiel retrato de objetos existentes tal y como ellos son. Un extracto de las Instrucciones que deben seguir los artistas..., redactadas por el entonces director del Real Jardín Botánico de Madrid, Casimiro Gómez Ortega, dice así:

eyes and hands". En: Knowledge and society: studies in the sociology of culture past and present (1986), 6, pp. 1-40; RUDWICK, M. J. S. (1976), "The emergence of visual language for geological sciences". History of science, 14, pp. 149-195; FLECK, L. (1986), "To look, to see, to know» in: Cohen, R. S. y Schenelle, T. (eds.), Cognition and Fact.

${ }^{3}$ Ver, por ejemplo, KeMP, M. (1990), "Taking it on trust: form and meaning in naturalistic representation", Archives of Natural History, 17 (2), pp. 127-188; BucHANAN, H. (1979), Nature into art: the treasury of great natural history books, London; Ellenius, A. (ed.) (1985), The natural sciences and the arts, Upsala; STAFord, J. (1984), Voyage into substance, Art., science, nature and illustrated travell account. 1760-1840, Cambridge Mas, MIT Press. En el caso concreto de las ilustraciones de las expediciones españolas ver: Soto Serrano, C. (1992), "Aspectos artísticos de la Real Expedición Botánica de Nueva Granada», Mutis y la Real Expedición..., Bogotá, Villegas Editores. 


\section{MAURICIO NIETO}

... [los] artistas se han de ceñir a copiar exactamente la naturaleza en sus producciones, especialmente vegetales, sin pretender adornarlas, ni añadir cosa alguna de su imaginación ${ }^{4}$.

A pesar de la insistencia de los botánicos en el realismo de sus ilustraciones, veremos cómo los resultados finales deben ser entendidos como formas ideales, producto de una minuciosa fabricación. En el mismo texto, Gómez Ortega explica:

[los artistas] no sólo se han de limitar a lo que precisamente determinen los botánicos por digno de ser dibujado; sino que lo han de hacer bajo su dirección, oyendo con docilidad las prevenciones que les hagan, ya sea para que se esmeren en el dibujo de esta, o la otra parte, que los botánicos tienen por más importante para el conocimiento y distinción de las plantas; y ya también para que en caso necesario la representen con separación y a veces de magnitud abultada 5 .

Es importante recordar que los dibujos no eran elaborados en el campo. Generalmente, el artista tenía como modelo un fragmento de la planta ya desposeído de su hábitat natural. Habiendo sido éste recolectado por otra persona, el dibujante tenía poca o ninguna familiaridad con la planta en su estado natural. Por otra parte, el elevado número de ejemplares no permitía la conclusión de las láminas durante los viajes, de manera que el artista se limitaba a elaborar un bosquejo de las plantas concentrándose en las características que, en opinión de los botánicos, serían necesarias para una apropiada clasificación Linneana. Una vez en el jardín botánico o en la imprenta una versión más elaborada de la ilustración era entonces concluida.

La selección y entrenamiento de los artistas es un tema de central interés que por motivos de espacio no discutiremos aquí con el debido cuidado. Sin embargo, vale la pena mencionar que José Celestino Mutis

${ }^{4}$ GÓMEz ORTEGA, C., «Instrucciones que deberán observar los dibujantes que pasan al Perú de orden de S. M. para servir con el ejercicio de su profesión en la expedición botánica», abril de 1777, art. 1. en: JaRAMILlo ARANGo, J. (1952), Relación Histórica del Viaje a que hizo a los Reinos del Perú y Chile, el botánico Don Hipólito Ruiz en el año de 1777 hasta el de 1788 en cuya época regresó a Madrid, Madrid, p. 416.

5 Ibid. 
fundaría su propia escuela de dibujo en Santa Fe de Bogotá, y manifestaría su predilección por jóvenes dóciles fácilmente instruidos a expertos pintores ${ }^{6}$. «Me ha sido más fácil, y siempre me lo será, tratar con gente más dócil aunque menos hábil», explica Mutis, "porque yo suplo por la instrucción que les doy la habilidad que les falta en los principios, y de este modo compenso la indocilidad de los oficiales españoles que siempre prueban mal en América» 7 .

Los pintores, vale la pena anotar, eran entrenados en el copiado de láminas y dibujos antes de trabajar sobre las plantas. Entre los papeles de Mutis hallamos bosquejos que presumiblemente constituyeron parte del entrenamiento de jóvenes pintores. En ellos encontramos repetidas anotaciones y correcciones sobre los dibujos en proceso de elaboración. Veamos algunos ejemplos:

La figura 1 corresponde a la serie «Sinanterologías», anatomías de la familia "Compositae». En la parte superior encontramos la siguiente observación: «El vilano un poco más largo, lo demás bueno». En la figura 2 vemos un diseño con doce diferentes tipos de vilanos que servirían de modelo de las posibles formas específicas de dicha estructura. En la figura 3 vemos otro ejemplo de la misma serie de la familia de las compuestas que, al igual que las anteriores, presumiblemente sirvieron de guía para el apropiado reconocimiento de las distintas estructuras florales y formas de las hojas. La anotación en la margen izquierda explica que los filamentos que representan anteras no son anteras sino unos filamentos comunes en muchas plantas de esta clase ${ }^{8}$.

Algunos de las ilustraciones inconclusas, que hoy se conservan en el Real Jardín Botánico de Madrid, nos permiten apreciar importantes elementos de su confección al igual que la sistemática selección de caracteres. En las figuras 4 y 5 podemos ver cómo ciertos elementos, la forma de las hojas, la estructura de la flor, el fruto y algunos colores, tienen prioridad.

\footnotetext{
6 Soto Serrano, C. (1992), op. cit., p. 146.

7 Mutis a Juan José Villaluenga, julio 10 de 1786, en: Archivo epistolar del sabio naturalista Don José Celestino Mutis, vol. 1, Bogotá: Instituto Colombiano de Cultura Hispánica, 1983, p. 313.

8 Serie anatomías, "Sinanterologías», Archivo Real Jardín Botánico de Madrid, M00174, 75, 76.
} 


\section{MAURICIO NIETO}

Este tipo de ejemplos, al igual que una considerable colección de anatomías y disecciones, constituyen el único registro gráfico del proceso de elaboración de las láminas y formación de artistas.

Estos y muchos otros ejemplos nos sugieren que en el proceso de aprendizaje el artista debe ser entrenado para reconocer formas y estructuras específicas y determinadas por la botánica del siglo XVIII y que el botánico visualiza las estructuras esenciales de la planta una vez ha dejado de observar la naturaleza y examina detenidamente esquemas y diagramas.

Tanto El Diario de la Expedición de Eloy Valenzuela como El Diario de observaciones de Mutis, contienen valiosa información sobre las tareas en que día a día se ocuparon Mutis y sus colaboradores. El viernes 30 de abril, 1784, Mutis escribe:

«Hoy gasté al principio de la mañana no poco tiempo en reconocer con mucha atención las flores y frutas de la Boymia acuatica, haciéndome traer por los herbolarios muchas plantas con sus flores...»9 .

Casi dos semanas más tarde, el jueves 13 de mayo, leemos en el diario de Mutis:

«Rizo concluyó a las tres de la tarde la Boymia. En esta lámina falta la división de la corola, que no se hizo por estar las flores casi cerradas...» ${ }^{10}$.

Numerosos ejemplos como éste nos indican cómo el terminado de una lámina se podría tomar semanas y en algunas ocasiones años de retoques y adiciones basados en nuevos y más completos ejemplares. "Cada lámina me cuesta mil suspiros», escribiría el botánico español,

«... la lámina que saliese de mis manos no necesitará nuevos retoques de mis sucesores, y cualquier botánico en Europa hallará representados los finísimos caracteres de la fructificación sin necesidad de venir a reconocerlos en su estado nativo" 11

9 Mutis, J. C. (1958), Diario de Observaciones, Bogotá. Instituto Colombiano de Cultura Hispánica, vol. II, p. 161.

10 Ibid., p. 202.

11 Muris, J. C., Flora del Nuevo Reino de Granada, vol. I, p. 102. 
La publicación de la Flora del Nuevo Reino de Granada no se iniciaría hasta 1954 cuando los gobiernos de España y Colombia decidieron hacer públicos los trabajos de Mutis y sus colaboradores. De tal manera que para estudiar la producción de grabados y publicación de las ilustraciones debemos ocuparnos de los trabajos de Hipólito Ruiz y José Pavón durante la composición de los primeros volúmenes de la Flora Peruvianae et Chilensis.

Las láminas elaboradas en la escuela de Mutis y los dibujos de la Flora Peruviana presentan marcadas diferencias técnicas y dos estilos notoriamente disímiles. Sin embargo, para el propósito del presente análisis me limitaré a señalar algunos elementos comunes en el proceso de elaboración y terminado de las ilustraciones.

Particularmente interesantes, son las anotaciones diarias de los botánicos españoles durante la publicación del primer volumen de la Flora desde $1793^{12}$. El documento revela una laboriosa y prolongada serie de correcciones, retocado y perfeccionamiento de las distintas láminas. En dicho diario encontramos repetidas anotaciones tales como, «Los botánicos continuaron con el arreglo de las partes de fructificación y con la corrección de ellas»" " . El dibujante aumentó algunas partes que se habían omitido...» ${ }^{14}$. «Los botánicos continuaron asistiendo a los dibujantes para la reducción y descargar los dibujos» ${ }^{15}$.

Las anotaciones de Ruiz y Pavón durante la elaboración de la Flora del Perú, al igual que El Diario de Observaciones de José Celestino Mutis ${ }^{16}$, nos permiten concluir que la labor de los pintores, bajo la supervisión de botánicos, consistía en un continuo mejoramiento, acabado y rectificación de las láminas utilizando nuevos ejemplares o partes florales recogidas con posterioridad. Algunos de los órganos para una apropiada diagnosis de la planta aparecen únicamente durante cortos períodos y no siempre simultáneamente en un único ejemplar. De manera que en una idealización gráfica de la planta el botánico acumula tiempo y espacio.

\footnotetext{
12 «Diario de los trabajos que van haciendo los botánicos y dibujantes de la expedición del Perú a fin de publicar la flora peruana y chilense desde el día 21 de febrero de 1793». Archivo del Real Jardín Botánico de Madrid, Div. IV, leg. 7, 4, 11.

13 Ibid., anotación $n .^{\circ} 18$.

14 Ibid., anotación n. ${ }^{\circ} 21$.

15 "Continuación del diario desde el 7 de abril de 1794». Archivo Real Jardín Botánico, IV, 12, 3, 5, n. ${ }^{\text {os }} 12-3-4$.

${ }_{16}$ Mutis, J. C. (1983), Diario de observaciones de J.C.M. (1760-1790), transcripción y prólogo de Guillermo Hernández de Alba, Bogotá. Instituto Colombiano de Cultura Hispánica. Ver por ejemplo, pp. 161, 175, 202, 245.
} 
Para llevar acabo los debidos ajustes se requerían no sólo los bosquejos hechos en América sino también ejemplares disecados y de una completa colección de literatura botánica y Floras recientemente publicadas en otras naciones europeas.

En una carta fechada el 26 de julio de 1792, firmada por Ruiz y Pavón, en la cual los botánicos solicitan los auxilios necesarios para formalizar sus borradores y disponerlos para la luz pública, manifiestan la necesidad de consultar otras publicaciones para comparar sus propios trabajos. "... que tengamos a la mano descripciones, dibujos y autores botánicos», explican Ruiz y Pavón, "para poder a un mismo tiempo que se revisan los borradores, consultar los autores y cotejar las láminas y descripciones de estas con las nuestras y con los herbarios» ${ }^{17}$.

Mutis, Ruiz y Pavón, o cualquier naturalista del siglo XVIII, al igual que muchos historiadores y comentaristas modernos, parecen estar de acuerdo en que las ilustraciones botánicas, son, o deben ser, fieles réplicas de objetos naturales y que dicho naturalismo era el resultado de una experiencia inmediata y directa de los dibujantes y botánicos con sus objetos de estudio. Sin embargo, tanto en la producción de las láminas de la Expedición al Nuevo Reino de Granada, como en la preparación de los grabados para la publicación de la Flora Peruvianae et Chilensis es claro que la confección de las láminas implicaba un prolongado proceso de ensamble estrechamente relacionado con un sistema de normas pre-establecidas comunes entre la mayoría de los naturalistas europeos, a saber, la filosofía linneana.

No debemos olvidar que en el sistema linneano las plantas son descritas no de acuerdo con sus rasgos particulares sino de acuerdo con sus características comunes a un grupo. En otras palabras, el éxito de la identificación de un nuevo espécimen no depende de su exhaustiva descripción sino de la verificación en éste de propiedades reconocibles y familiares en un sistema determinado de clasificación.

Veamos un conocido ejemplo de la Flora de Mutis y la versión final de una planta de quina. En la figura 6 vemos la ilustración de la especie Cinchona cordifolia, la cual no representa nada semejante a un árbol de Cinchona sino la parte terminal de una de sus ramas extraordinariamente cargada de flores y frutos cuidadosamente dispuestos para destacar sus características esenciales de acuerdo con la taxonomía contemporánea.

17 «Solicitud de libros de Hipólito Ruiz y Josef Pavon». Archivo Real Jardín Botánico de Madrid, Div. IV, leg. 7, 4, 4. 


\section{PRESENTACIÓN GRÁFICA, DESPLÄZAMIENTO Y APROBACIÓN DE LA NATURALEZA}

La lámina, además de hacer evidente las habilidades del artista, es visiblemente esquemática y casi geométrica en su composición. En ella podemos observar sus flores y frutos en diferentes estadios de desarrollo, el cáliz, y el número de pétalos. Sin embargo el rasgo más evidente de la lámina son las hojas, cuya forma, en el sistema Linneano, es esencial para una adecuada diagnosis de la especie. Las hojas, nos diría Linneo, "contienen la más natural y la más elegante diferencia...." ${ }^{18}$.

Fiel a Linneo, Mutis, en su clasificación del género Cinchona, estableció cuatro diferentes especies, las cuales, como podemos observar en fig. 7 fueron clasificadas de acuerdo con la forma de sus hojas: Cinchona lanceifolia (forma de lanza), C. oblongifolia (forma oblonga), C. ovalifolia (elíptica) y $C$. cordifolia (acorazonada) ${ }^{19}$.

Es interesante notar que estas cuatro especies, en la opinión de Mutis; correspondían a los colores naranja, amarillo, rojo y blanco de las cortezas de las distintas variedades de quina en el comercio, y que dicho criterio, al igual que estas cuatro categorías, eran comunes entre recolectores en América. La clasificación del genero Cinchona de Mutis la podemos entender entonces como la traducción de un criterio local a un lenguaje linneano propio de los naturalistas europeos de la ilustración. Un lenguaje, cuya proclamada universalidad sirvió de herramienta para hacer público el descubrimiento y apropiación de nuevas especies.

Otro elemento particularmente importante de las ilustraciones botánicas, son las disecciones comúnmente localizadas en la parte inferior del dibujo. En ellas encontramos las claves esenciales para una completa clasificación de la planta, que para Linneo y sus contemporáneos, representan rasgos esenciales, «La expresión de las ideas del Creador» El cáliz, la flor, los pétalos visibles en su totalidad y una disección de la flor con sus órganos reproductores. En este caso particular encontramos cinco estambres y un único pistilo, enmarcando la planta en la clase Pentandria y al orden Monogynia.

Los naturalistas del siglo XVIII, podríamos concluir, se ocuparon de la movilización, recopilación, codificación, y exhibición de los objetos de la naturaleza. El mundo vegetal, no es fácilmente transportable. Las plantas son objetos delicados que difícilmente sobreviven largas jornadas

\footnotetext{
18 Linnaeus, C. (1938), The Critica Botanica of Linnaeus, London: Ray Society, art. 277.

19 Ver Mutis, J. C. (1808), «El arcano de la quina», en Semanario del Reyno de la Nueva Granada, Wellcome Library, American Room.
} 


\section{MAURICIO NIETOO}

marinas, y cuya aclimatación presenta innumerables obstáculos. Las láminas, por el contrario, una vez terminadas, - utilizando la terminología del sociólogo francés Bruno Latour - se convierten en «móviles inmutables» ${ }^{20}$; los dibujos, una vez elaborados permanecen inalterados, se hacen transportables, fácilmente estudiados, comparados, almacenados, reproducidos y presentados al público en forma idéntica. Aún más significativo es el hecho de que una vez se ha nombrado la especie y se ha encasillado ésta en un sistema de clasificación, los dibujos, cumplen la función de tipos taxonómicos. Formas ideales que no sólo parecen corroborar la idea de «especies inmutables» sino que adquieren el estatus de descubrimiento científico.

La noción tradicional de "descubrimiento», nos sugiere un individuo, quien, mientras recorre los bosques americanos y en un momento de suerte o astucia encuentra por primera vez objetos cuya existencia es independiente y precede a su descubridor. Como hemos visto, el «descubrimiento" de un nuevo genero o especie, lejos de ser un evento que tiene lugar en un momento determinado en algún lugar remoto, debe ser entendido como un proceso prolongado de elaboración en el cual lo inconmensurable se hace conmensurable, lo ajeno se domestica, lo extraño se hace familiar y se conquista ${ }^{21}$. Los objetos naturales y las culturas extrañas representaron una amenaza para las aspiraciones europeas de control global. Sin embargo, la historia natural y su carácter clasificador permitió fragmentar la naturaleza en unidades fácilmente incorporadas en un sistema, que como el linneano corroboraba un orden social y religioso propio de la Europa de la Ilustración. El artista, al seleccionar o destacar ciertos elementos y no otros, cumple una función central en este proceso. Sólo entonces, la especie o el género pueden ser movilizados, archivados, publicados y reconocidos como descubrimientos y posesiones.

20 Latour, B. (1987), Science in Action, Milton Keynes, Open University Press, p. 227.

21 Para un estudio sociológico de la idea de "descubrimiento" ver: BranNigan, A. (1981), The social basis of scientific discovery, Cambridge: Cambridge University Press; SCHAFFER, S. (1986), "Scientific discoveries and the End of Natural Philosophy». En: Social studies of science, London: Sage, vol. 16, pp. 387-420.

La idea de "descubrimiento" como un acto de posesión ha sido explorada por PAGDEN, A. (1993), European encounters with the New World: from Renaissance to Romanticism. New Haven and London: Yale University Press; GreenblatT, S. (1991), Marvelous possessions: the wonder of the New World, Oxford, Claredon Press. 
PRESENTACIÓN GRÁFICA, DESPLAZAMIENTO Y APROBACIÓN DE LA NATURALEZA
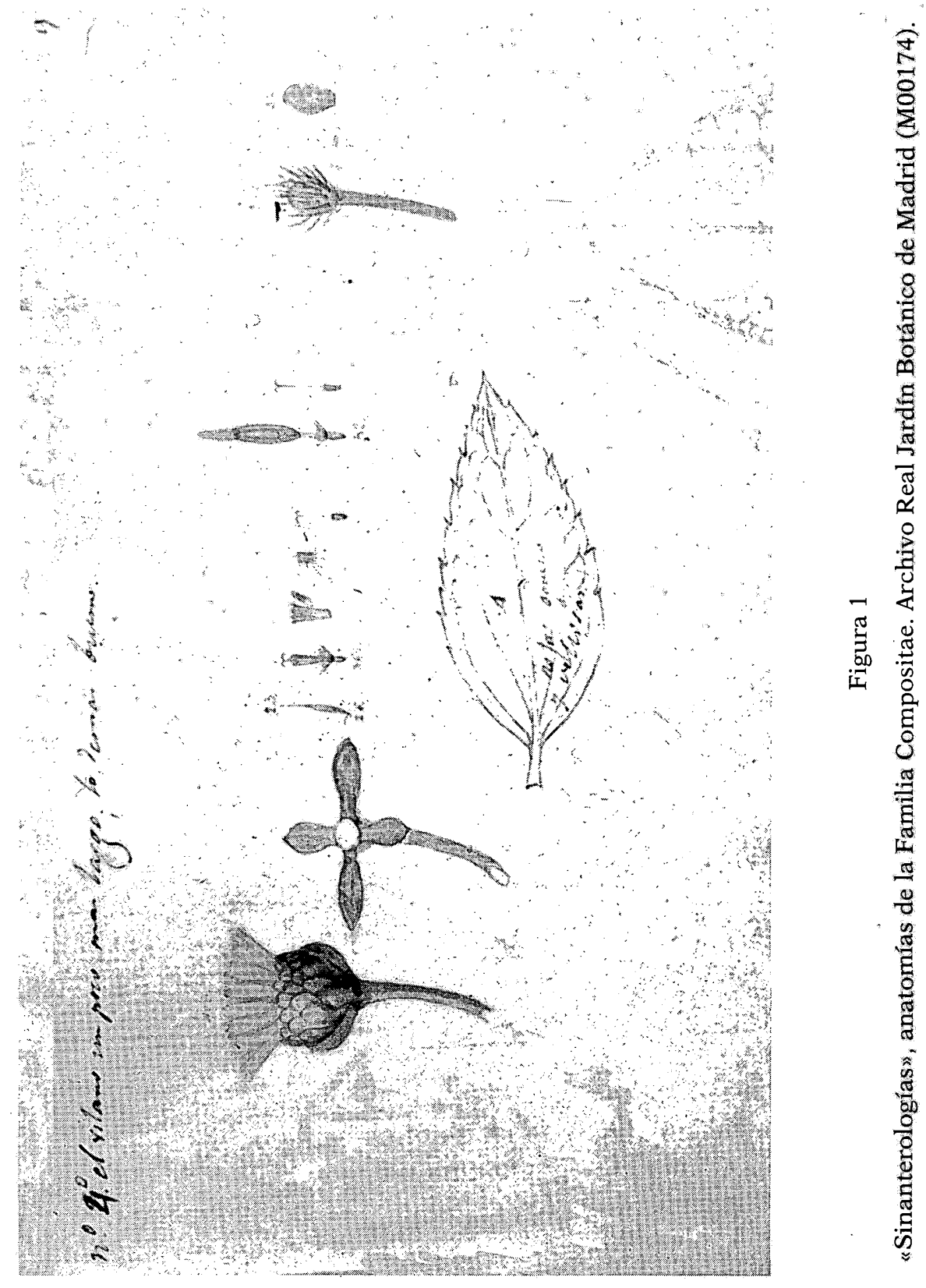

Asclepio-Vol. XLVII-2-1995

101 
MAURICIO NIETO

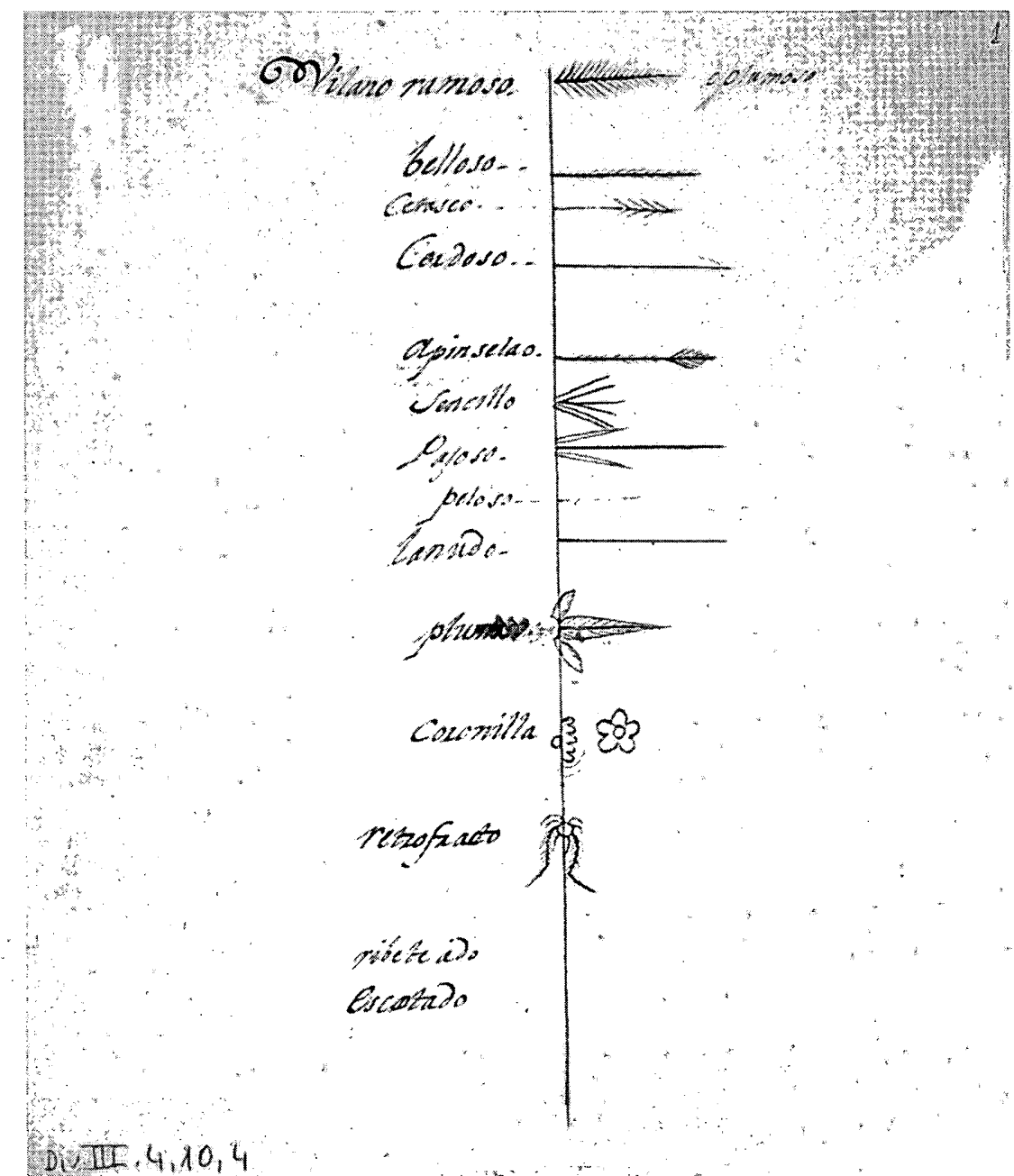

Figura 2

«Vilanos». Doce tipos diferentes de vilanos. Archivo Real Jardín Botánico de Madrid, Div. III, Leg. 4, 10, 4. 
PRESENTACIÓN GRÁFICA, DESPLAZAMIENTO Y APROBACIÓN DE LA NATURALEZA

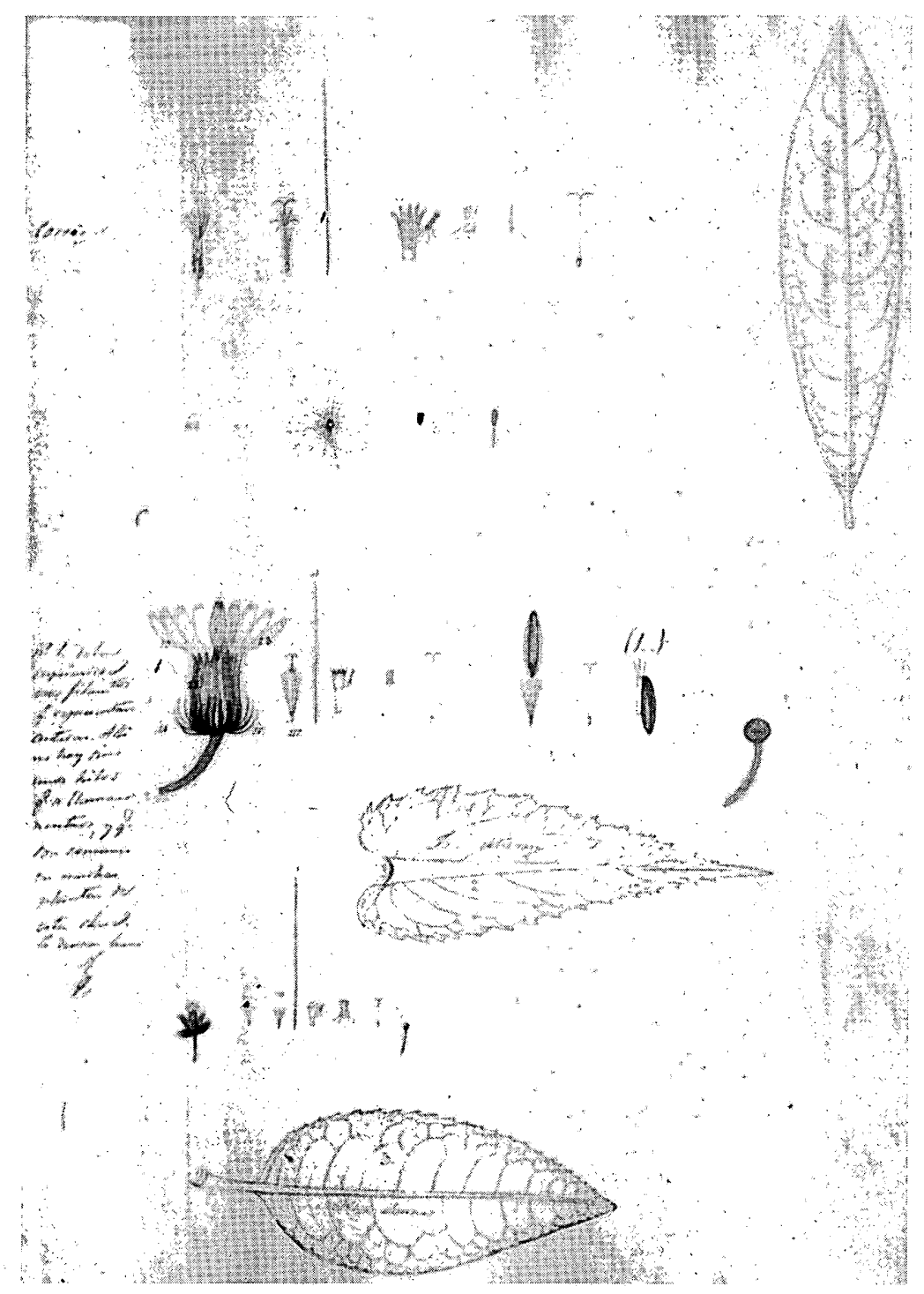

Figura 3

«Sinanterologías», anatomías de la Familia Compositae' Archivo Real Jardín Botánico de Madrid (M00174). 
MAURICIO NIETO



Figura 4

Bosquejos para la Flora del Nuevo Reino de Granada, Familia Passifloracea. Archivo Real Jardín Botánico de Madrid (M00578). 
PRESENTACIÓN GRÁFICA, DESPLAZAMIENTO Y APROBACIÓN DE LA NATURALEZA

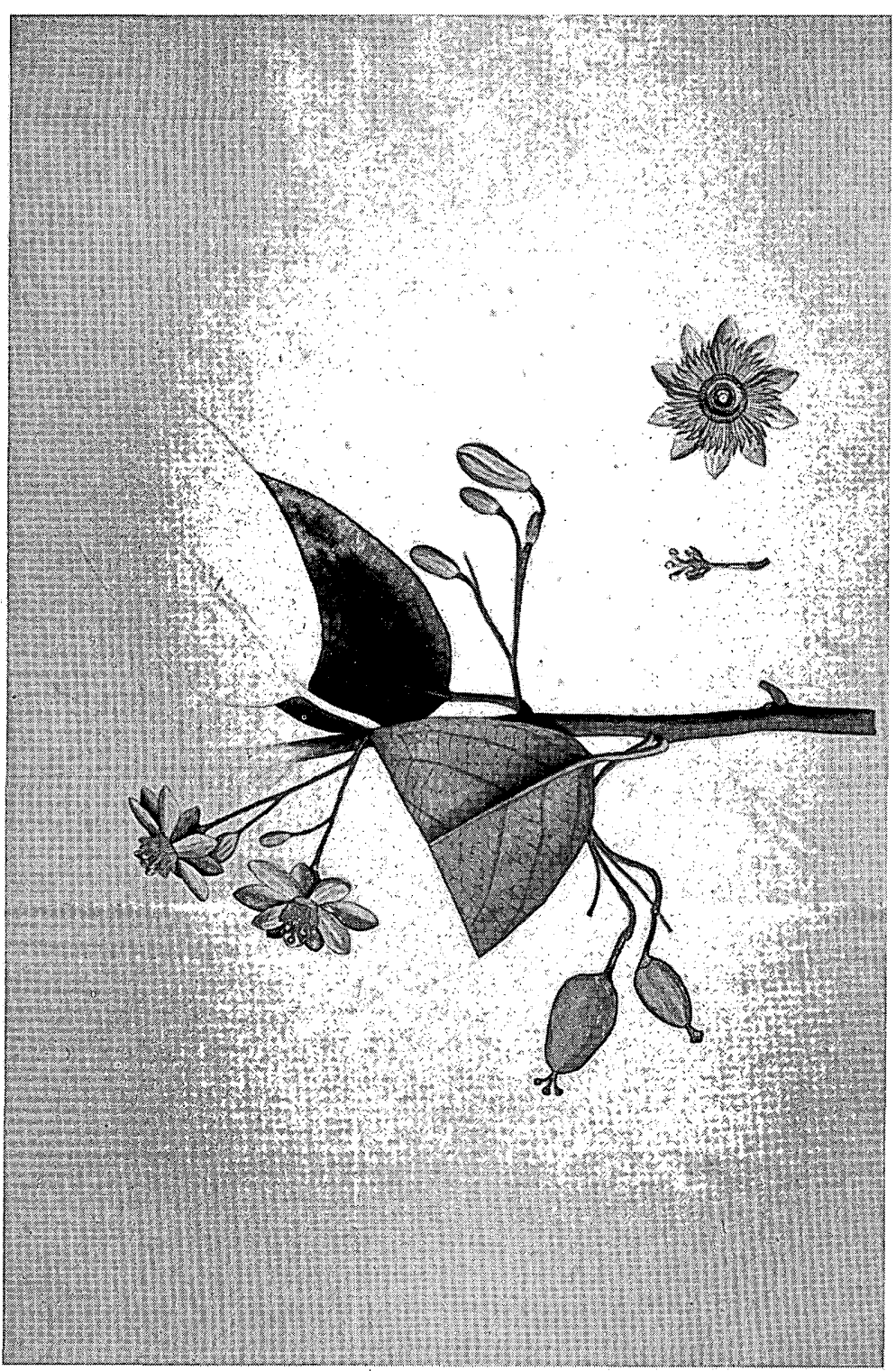

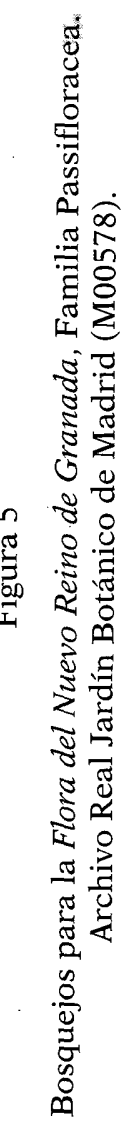

Asclepio-Vol. XLVII-2-1995

105 


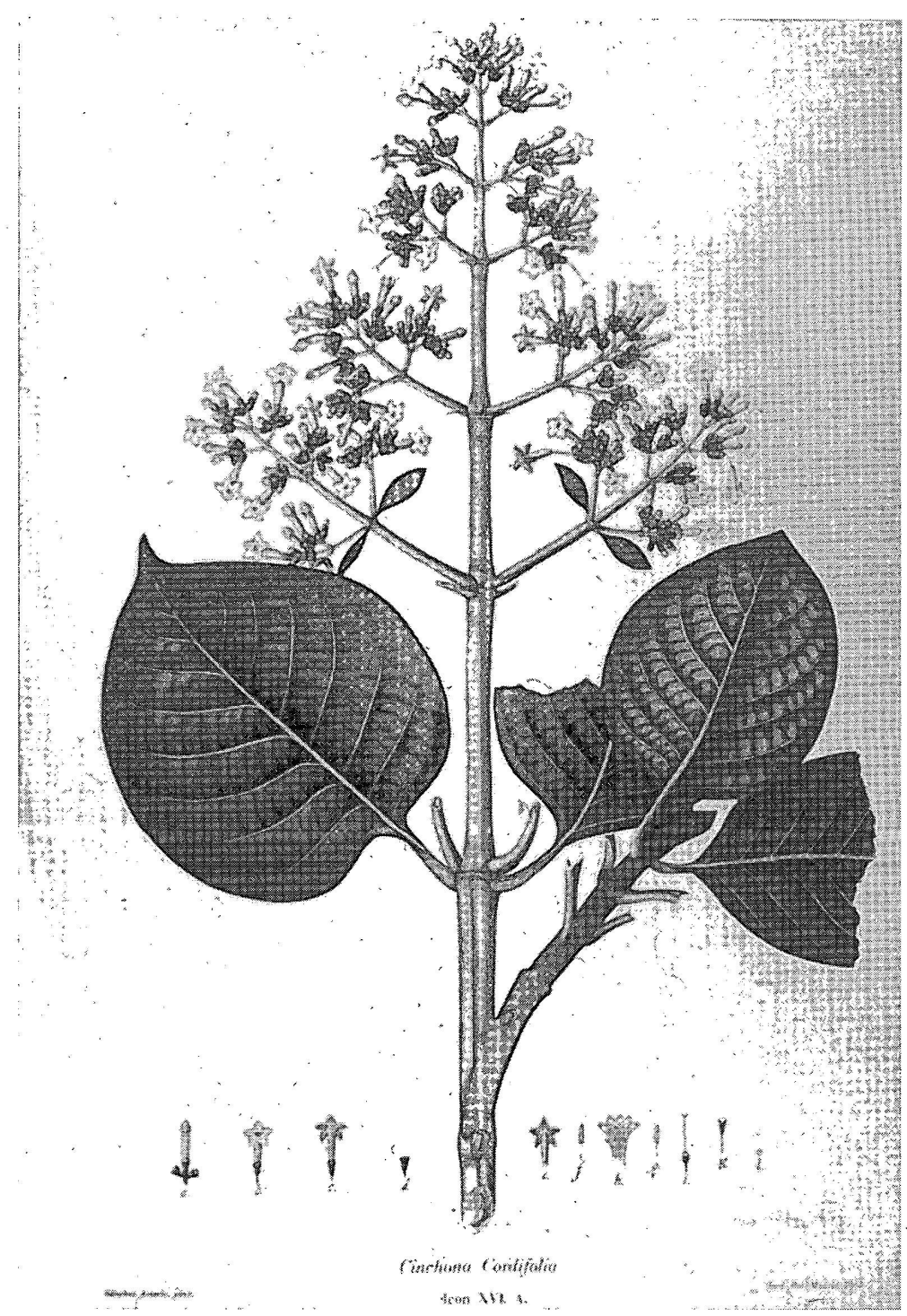

Figura 6

Cinchona cordifolia, Icon $16 \mathrm{~A}$

Flora de la Real Expedición Botánica del Nuevo Reino de Granada 
PRESENTACIÓN GRÁFICA, DESPLAZAMIENTO Y APROBACIÓN DE LA NATURALEZA

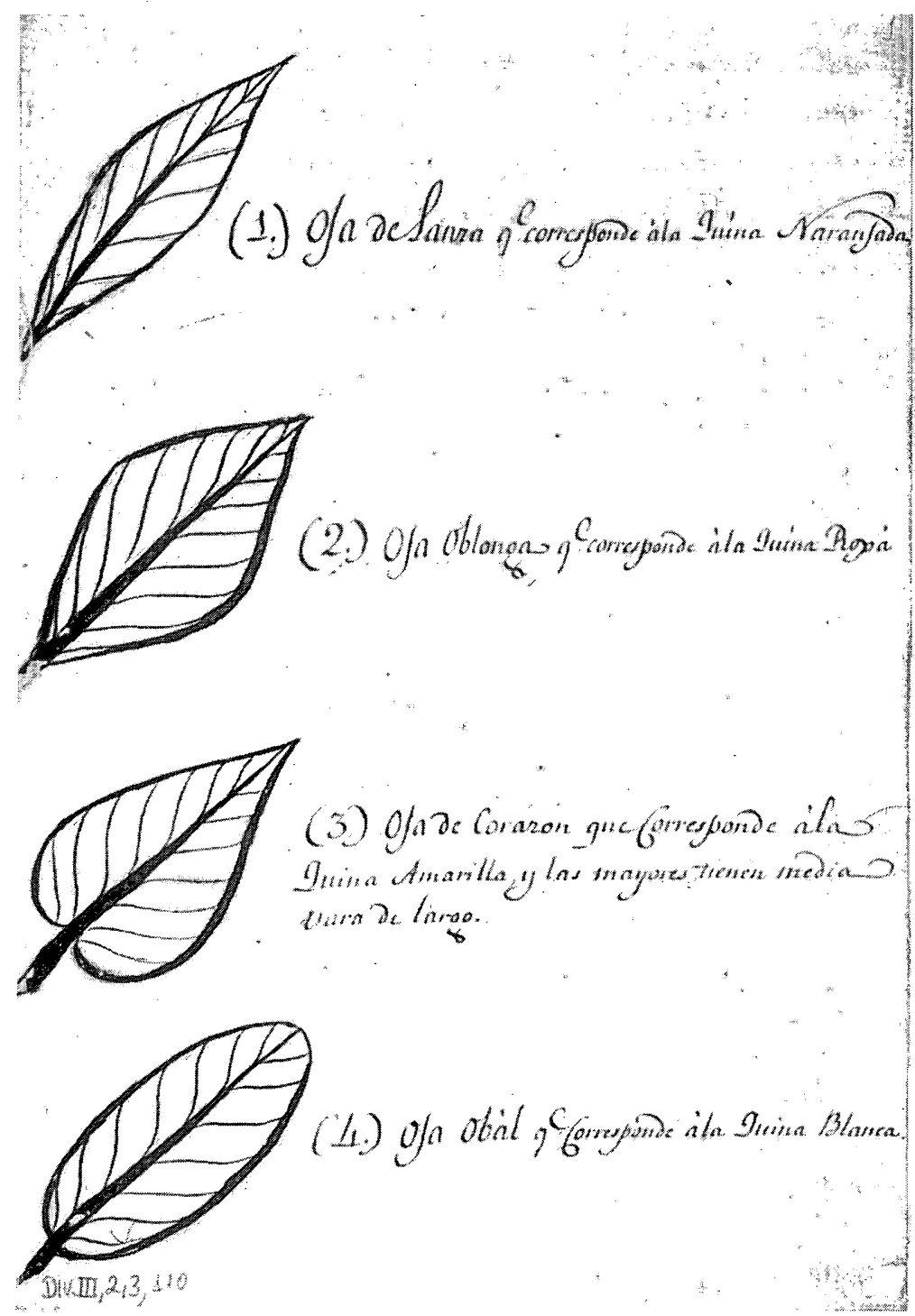

Figura 7

Cuatro especies de Cinchona de Mutis de acuerdo con la forma de sus hojas. Archivo Real Jardín Botánico de Madrid, Div. III, Leg. 2, 3, 110. 